\title{
Electronic Solution for Smart Electric Metering over Power Line
}

\author{
Vishal K. Ovhal \\ Electronics Department \\ Department of Technology \\ Shivaji University, Kolhapur
}

\author{
U.L. Bombale, PhD \\ Electronics Department \\ Department of Technology \\ Shivaji University, Kolhapur
}

\begin{abstract}
A World without electronic is just likes human body without soul. Electronics plays very important role in human life. We are surrounded by electronic devices such mobile phone, television, computer etc. Power line communication (PLC) is a best electronic mean for data transmission. Using power line communication remote meter reading, power supply control and Electricity theft detection can be possible. This meter is called as smart because it transmit energy consumption units automatically through existing power lines and calculate bill amount. . In this detection system, separate energy meter is used which is located at distribution pole stores the value of energy consumed by all subscriber at that connection point. The stored energy value is compared with the total value at main energy meter situated at individual subscriber's premises. In case of any difference between two recorded energy values, an error signal is generated. The architecture of the system is presented. In this paper, the above said process is totally automatic and the communication is made possible entirely through the power line
\end{abstract}

\section{Keywords}

Illegal electricity usage detection; power line communication; power line communication (PLC) modem; power supply control; Remote meter reading.

\section{INTRODUCTION}

Electricity is directly affects the economic growth of the country. So it becomes necessary to keep watch and control usage of electricity. As the billing is done manually the probabilities of errors and manipulations while observing will be more. Using automation the drawbacks of the present system can be eliminated and the system can be made more efficient. A system can be developed which will monitor the energy consumption of subscriber. The system should also be able to communicate with central authority through power line. Thus electricity theft detection system has become a necessity for most energy suppliers. Power line communication has many services on the data transfer via power line without using extra cables Remote meter reading system is an important application in this regard due to every user connected to each other and central station through power line [1]. It is a technique to facilitate remote energy consumption reading. It is clearly known that using electricity illegally may indirectly affect the economic state of a country negatively. On the other hand, planning of national energy for a country becomes difficult in case of unrecorded usage. Illegal electricity may be a serious problem in many countries like India. This problem has been attempted to be resolved by special skills of humans. These methods could not give the optimum solutions due to their impracticalities. Today, we have many chips which can be used for digital energy metering and PLC modems. At this point of technological advancement, the problem of illegal usage of electricity must be solved electronically, without any human control [2].

\subsection{Components of Proposed System}

Power is the soul of world which is related to the electricity and "electricity" is the word which now controls the world. So, proper utilization of this valuable thing is of great important to us. Hence, it is necessary to measure electric power consumed by customer. The components of proposed system is shown in fig. 1

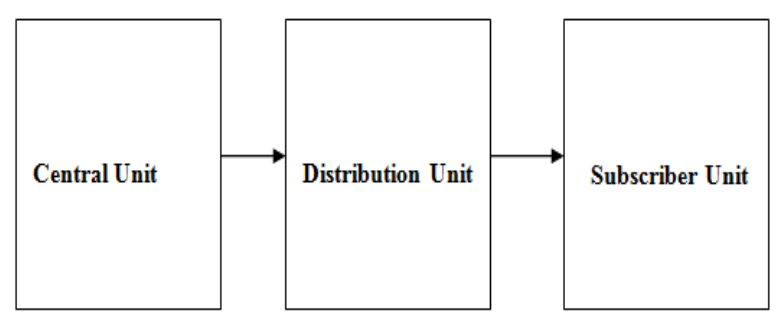

Fig.1 Component of proposed System

\section{WORKING OF SYSTEM}

An electricity theft detection system is a real time power monitoring system. It consists of three units situated at different locations. The different units are namely as follows

\section{Central unit \\ 2. Distribution unit (Pole unit) \\ 3. Subscriber unit}

The central unit controls the other two units situated far away from it. The control is done via power line communication (PLC). Second unit is the unit on pole which is located at the connection point between main line and subscriber. This unit is usually situated on electricity pole therefore it is not possible for anyone to access it [3]. The third unit is situated at subscriber's house and repeated for every subscriber. In the automatic Electric billing system the value of power consumed by the subscribers is stored at subscriber's unit. The recorded data for every subscriber is sent to central unit. In response to the reading central unit calculate bill. If bill will not paid in given time span then cut that subscriber power supply using relay contactor.

In the detection system the value of power consumed by the subscribers is stored at subscriber's unit. The recorded data for every subscriber is sent to central unit. On the other hand, energy meter located at the connection point also read the power consumed and send the data to central unit. The central unit has two recorded data, one which comes from pole unit 
and the other which comes from subscriber's unit. This two recorded power is compared at the central unit. In case of any difference between the data recorded at two units, an error signal is generated. This indicates that there is illegal power usage in the network. The transmission and reception of data and control signals between the two units is done via power line [4]. A contactor is included to the system at subscriber's location to turn off the power automatically.

\section{SYSTEM DESIGN}

\subsection{Central unit:}

The central unit or EB office unit consists of microcontroller, power line communication (PLC) modem and personal computer. The microcontroller is interfaced with personal computer (PC) and PLC modem. To control the operation, various commands from $\mathrm{PC}$ can be given to microcontroller [5].

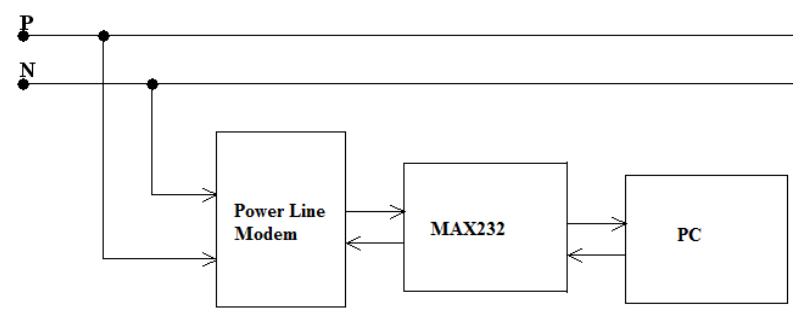

Fig.3 Central Unit (EB office End)

\subsection{Subscriber and Distribution Unit:}

These unit contains microcontroller, power line communication modem and energy meter. Subscriber unit is repeated for every subscriber. The subscriber's unit keeps the record of power consumed by respective subscriber and transmits the reading to the host unit via power line. The distribution unit keeps the record of power consumed by all subscribers at that point and transmits the reading to the host unit via power line. PLC modem performs FSK modulation for transmission of digital data over power line [6]. The unit also follows various commands given by host unit.

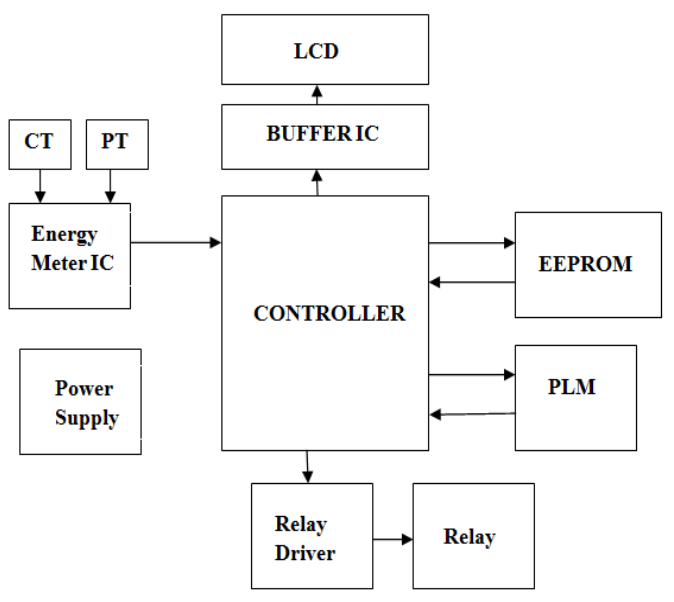

Fig.4 Distribution and Subscriber End Unit

\subsection{Current Transformer (CT) and} Potential Transformer (PT):

The Current Transformer (CT), is designed to produce an alternating current in its secondary winding which is proportional to the current being measured in its primary.
The Potential Transformer (PT) is used to step down the voltage to a lower range that will work with a Watt Node meter [7].

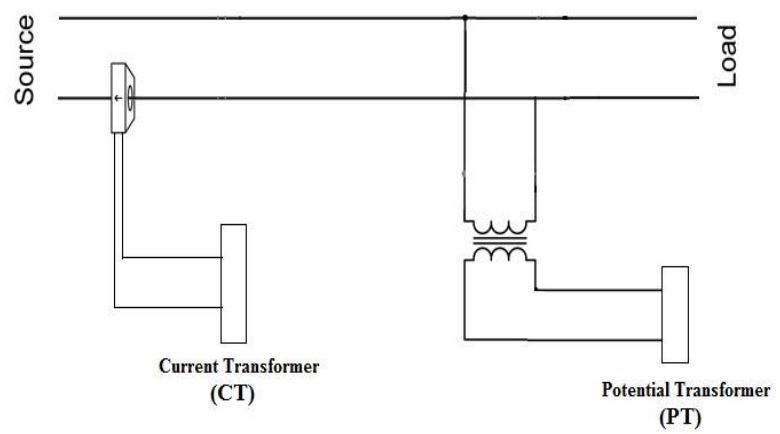

Fig. 5 CT-PT connection Diagram

\subsection{Power Line Modem}

Power line modem is useful to send and receive serial data over existing $\mathrm{AC}$ mains power lines of the building. It has high immunity to electrical noise persistence in the power line and built in error checking so it never gives out corrupt data. The modem is in form of a ready to use circuit module, which is capable of providing 9600 baud rate low rate bi-directional data communication. Due to its small size it can be integrated into and become part of the user's power line data communication system [8].

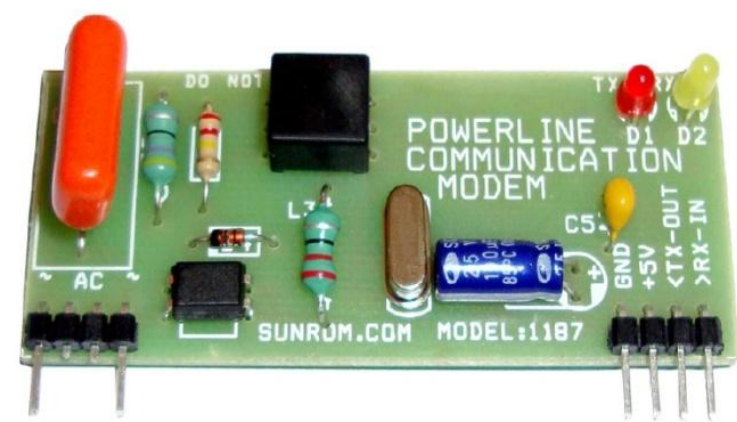

Fig.6 Power Line Communication Modem

This modem Supports Transmit and Receive serial data at 9600 bps over a $230 \mathrm{~V}$ power lines. It has a Data Tx/Rx LEDs for indication. It is powered from $5 \mathrm{~V}$ regulated power supply with Low Cost \& Simple to use. This modem has built in Error Checking facility and direct interface with microcontroller UART Txd, Rxd pins. The data transmitted and received by modem is FSK modulated.

\section{ENERGY CALCULATIONS}

It is important not to confuse power and energy, although they are closely related. Just remember that power is the rate at which energy is delivered, not an amount of energy itself [9]. With simple algebra, can turn the formula above for power around to solve for energy instead, and write:

Power $=$ Current $(I) \times$ Voltage $(V)$

$$
\text { Energy }=\text { Power } x \text { Time }
$$

$$
\text { Units }=\frac{\text { Energy }}{1000}
$$


Units of energy and power are joules and watts respectively. One kilowatt hour is the amount of energy that would be converted by a one thousand watt appliance when used for one hour.

When 1000 watts load is turn ON for one hour then lunit energy is consumed by that load

\section{SOFTWARE FLOW CHART}

Fig.7 shows flow of program for a generation of control signals and accordingly code is written in embedded $\mathrm{C}$ and compiled on $\mu$ Vision Keil4 IDE.

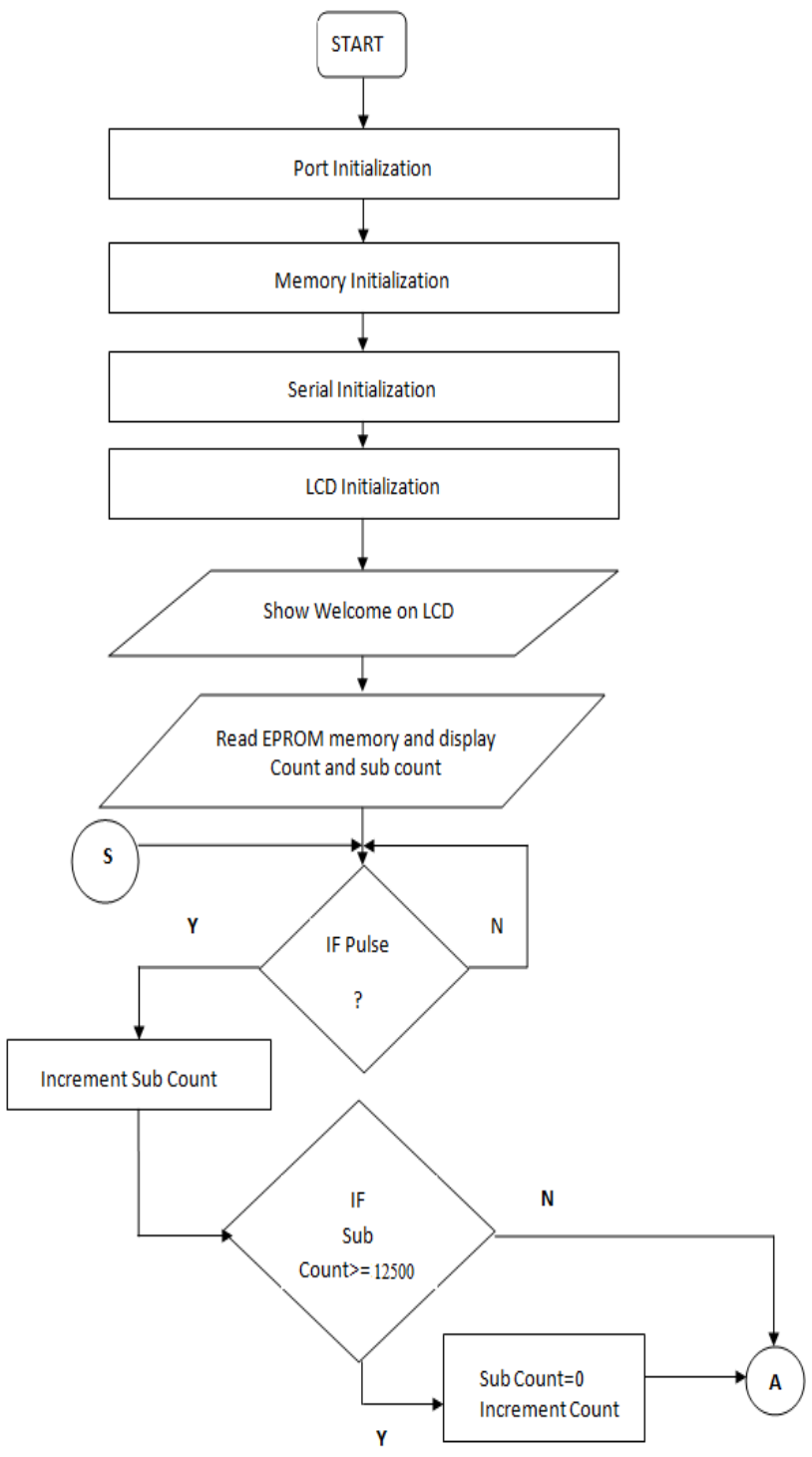

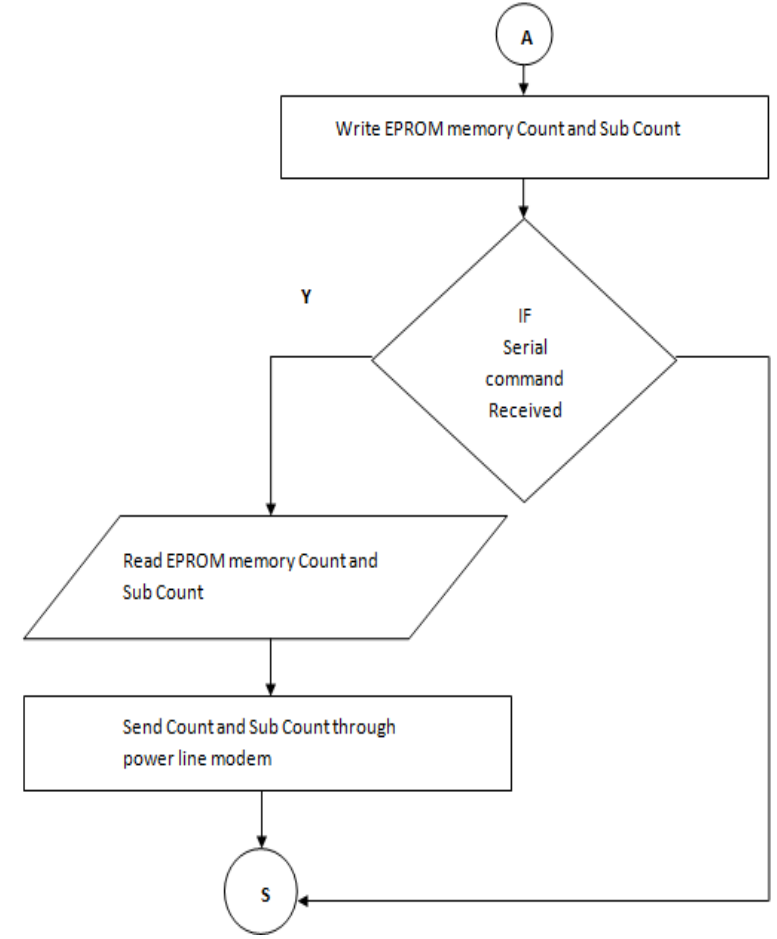

Fig.7 Programming Flow

\section{RESULTS}

To test the system required loads to be applied at the subscriber/distribution end. The loads needed to be different to show corresponding difference in the consumed power. The number of pulses produced at the output of ADE7751 is proportional to the power consumed by the load attached at the subscriber/distribution end. Practically, in the EB system, 125000 pulses are considered as one unit, i.e. the power consumed by a 1000 watts load for one hour is equal to one unit.

\section{VISUAL BASIC 6.0 OUTPUTS}

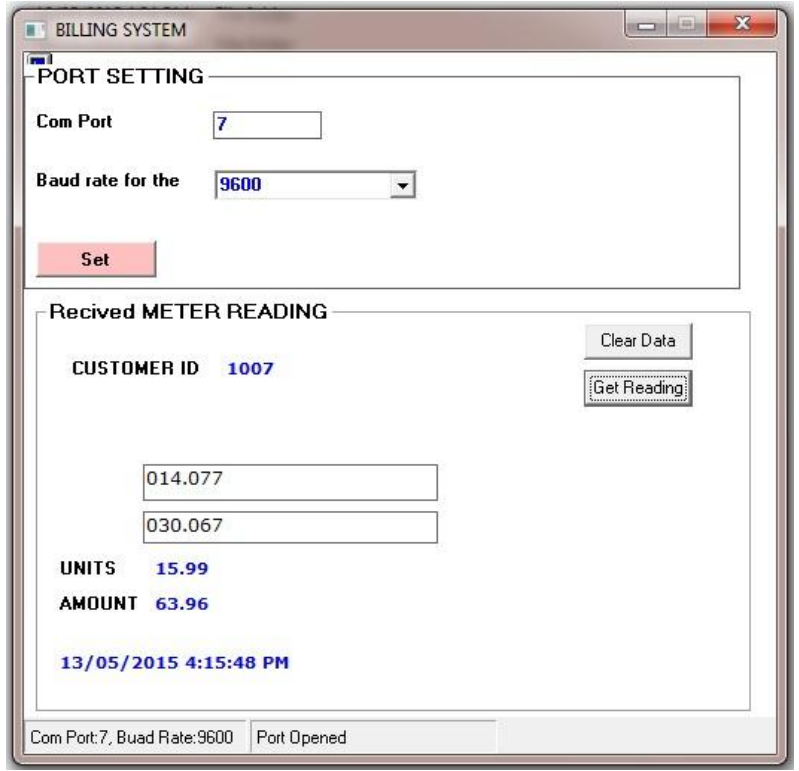

Fig. 8 Electric billing system 


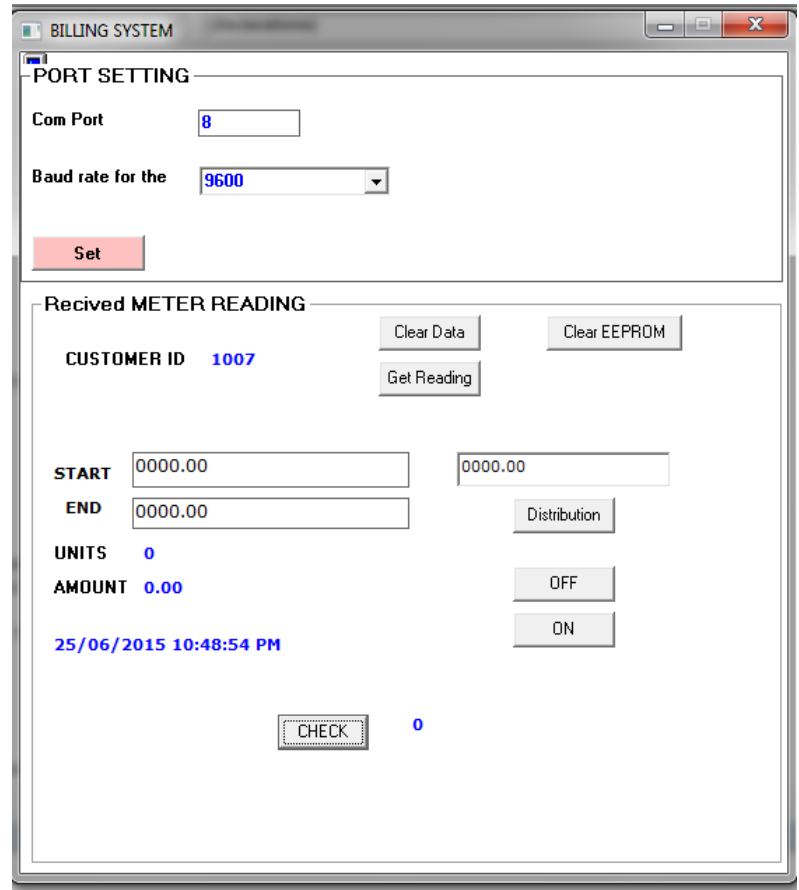

Fig. 9 Electric billing without Electricity Theft

\section{For different Load:}

Input Voltage $=230 \mathrm{~V}$ (constant)

Table 1. Comparison of results

\begin{tabular}{|c|c|c|c|c|c|}
\hline $\begin{array}{c}\text { Load } \\
\text { value } \\
\text { (W) }\end{array}$ & $\begin{array}{c}\text { Load } \\
\text { Current } \\
\text { (Amp) }\end{array}$ & $\begin{array}{c}\text { Time } \\
\text { for 0.1 } \\
\text { unit }\end{array}$ & $\begin{array}{c}\text { Standard } \\
\text { meter } \\
(\text { Kwh })\end{array}$ & $\begin{array}{c}\text { New } \\
\text { meter } \\
(\text { Kwh })\end{array}$ & $\begin{array}{c}\text { Calculated } \\
\text { Units } \\
(\text { Kwh })\end{array}$ \\
\hline 40 & 0.17 & $5 / 2 \mathrm{Hrs}$ & 0.1 & 0.1 & 0.1 \\
\hline 60 & 0.26 & $5 / 3 \mathrm{Hrs}$ & 0.1 & 0.1 & 0.1 \\
\hline 100 & 0.43 & $1 \mathrm{Hrs}$ & 0.1 & 0.1 & 0.1 \\
\hline 200 & 0.86 & $1 / 2 \mathrm{Hrs}$ & 0.1 & 0.1 & 0.1 \\
& & & & & \\
\hline
\end{tabular}

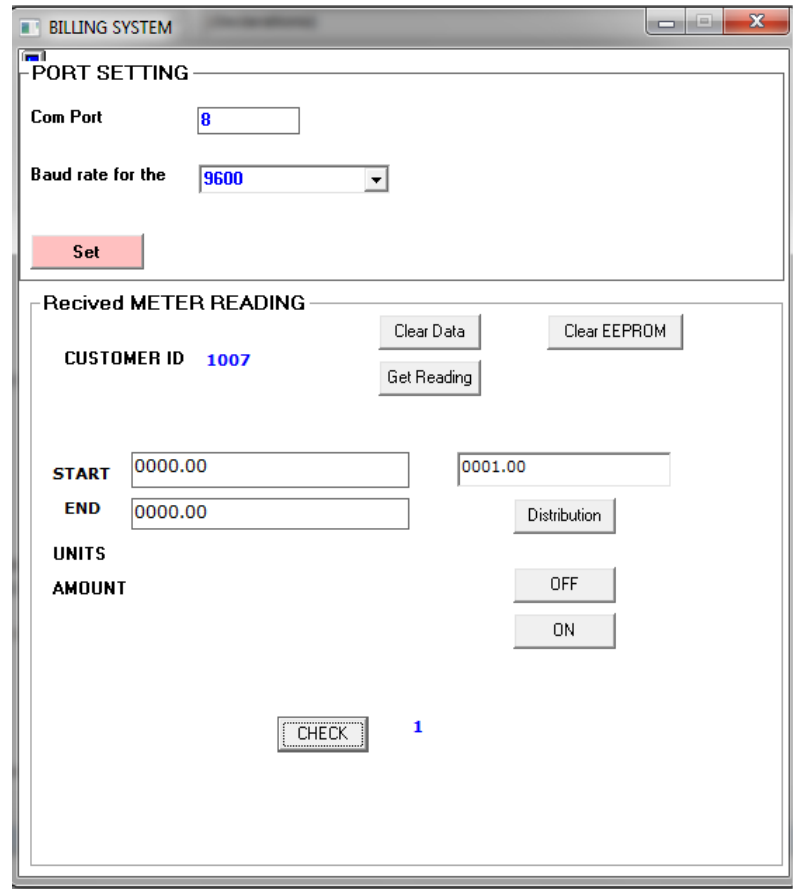

Fig. 10 Electric billing with Electricity Theft

\section{ACKNOWLEDGMENTS}

The satisfaction that accompanies the successful completion of any task would be partial without mention of the people who made it materialize with their constant guidance, support and encouragement. I would like to express my gratitude to everyone for their efforts that have directly or indirectly provided their ideas, time and energy towards successful completion of my project.

\section{CONCLUSIONS AND FUTURE IMPROVEMENTS}

The interesting feature about the device is that it communicates solely through the power lines. This is an implementation of data transmission through power lines. A successful implementation of this technology would open the door to new data services that could also be provided through the power lines. The system is entirely designed to work on single phase, but this can be further extended to work on 3 phase also. Transmission distance for the designed power line modem is few meters, can be improved by upgrading the power line modem. For higher loads exact design of current transformers will provide efficient output. By encoding the communications can be made much secured.

\section{REFERENCES}

[1] Raja, G.T. "Electricity consumption and automatic billing through power line", Power Engineering Conference, 2007, pp. $1411-1415$.

[2] Bharath, P "Wireless automated digital energy meter", Sustainable energy technologies, International conference, 2008, PP. $564-567$.

[3] Sungwook kim, Eun Young Kwon,Myungsun Kim, Jung Hee Cheon, seong-ho Ju, Young Hoon Lim, Moon-seok Choi "A secure smart-metering protocol over apower line communication" IEEE transaction on power delivery, Vol. 26, No. 4, October 2011, pp. 2370-2379. 
[4] Poonam Borle, Ankita Saswadkar, Deepali Hiwarkar, Rupali S. Kad "Automatic meter reading for electricity using power line communication" International Journal of Advanced Research in Electrical, Electronics and Instrumentation Engineering Vol. 2, Issue 3, March 2013.

[5] Chunjuan WEI _ Junjie YANG "Implementation of Automatic Meter Reading System Using PLC and GPRS" Journal of Information \&Computational Science 8:16 (2011)4343-4350
[6] Al-Qatari, S.A. “ Microcontroller - based automated billing system", Industrial automation and control: Emerging Technologies, 1995, pp. 517 - 523.

[7] Voltage Transformer or Potential Transformer Theory http://www.electrical4u.com/voltage-transformer-orpotential-transformer-theory.

[8] Powerline Communication Modem (PLC) http://www.sunrom.com/p/powerline-communicationmodem-plc sheet

[9] Wikipedia: http://www.wikipedia.com 